\title{
The Relationship between Bladder, Periarterial and Somatic Neuropathy in Diabetes
}

\author{
Ryuji Sakakibara ${ }^{1}$, Osamu Takahashi ${ }^{2}$, Haruka Nishimura ${ }^{2}$, Fuyuki Tateno ${ }^{1}$, Masahiko Kishi ${ }^{1}$, \\ Yohei Tsuyusaki ${ }^{1}$, Yosuke Aiba ${ }^{1}$ and Ichiro Tatsuno ${ }^{3}$
}

\begin{abstract}
:
Objective Diabetes commonly affects the bladder nerves. However, the relationship among bladder, periarterial and somatic neuropathy in diabetes is not well known. In the present study we investigated these relationships.

Methods A total of 110 diabetic subjects were enrolled in the study. All were referred for screening for diabetic neuropathy, irrespective of their symptoms. The patients included 61 men and 49 women; the mean age was 59.3 years (31-85 years); the mean disease duration was 14.0 years (5-30 years); and the mean HbA1c value was $10.1 \%$ (5.1-16.3\%). We performed a nerve conduction study (NCS, A-alpha/beta and B fiber), ultrasound-based measurement of the post-void residual (PVR) volume (abnormal, $>50 \mathrm{~mL}$, mainly Adelta/C fiber) and postural blood pressure measurement (abnormal, $>-20 \mathrm{mmHg}$, A-delta/C fiber). Fisher's exact probability test and Student's $t$-test were used to analyze the significance of differences.

Results NCS abnormality, an abnormal PVR volume, and postural hypotension were noted in 74, 19, and 36 of the subjects, respectively. There were clear relationships between NCS and an abnormal PVR volume $(\mathrm{p}<0.05)$, postural hypotension and an abnormal PVR volume $(\mathrm{p}<0.05)$, or NCS and postural hypotension $(\mathrm{p}<$ 0.01). There were also subjects who had NCS abnormality alone, a high PVR volume alone or postural hypotension alone. An abnormal PVR volume was not associated with the HbAlc value, but was clearly related to the duration of diabetes $(\mathrm{p}<0.05)$.

Conclusion Bladder dysfunction was correlated with somatic and periarterial neuropathy. On the other hand, $16 \%$ of the cases of bladder dysfunction occurred in patients without somatic or periarterial neuropathy; thus, the regular measurement of the PVR volume is necessary.
\end{abstract}

Key words: diabetes, bladder, postural hypotension, diabetic neuropathy, small fiber neuropathy

(Intern Med 57: 2165-2168, 2018)

(DOI: 10.2169/internalmedicine.9749-17)

\section{Introduction}

Diabetes $(1,2)$ commonly affects the bladder nerves (3). Such patients often experience difficulty in emptying, a large post-void residual urine volume, reduced bladder sensation, and bladder over-activity (3). The associations between bladder and somatic neuropathy in patients with diabetes have been reported in various studies; the associated findings have included somatic pain sensation (somatic $\mathrm{A} \delta / \mathrm{C}$ small fiber) (3), nerve conduction in the limbs (somatic large fiber) $(4,5)$, and sympathetic skin responses (sweating; autonomic A $\delta / \mathrm{C}$ small fiber) $(6,7)$. However, it is not well known whether bladder dysfunction occurs without somatic neuropathy, or whether bladder dysfunction is associated with postural hypotension. To answer this question, we performed three simple objective tests in diabetic patients.

\section{Materials and Methods}

A total of 110 subjects who fulfilled the diagnostic criteria for type 2 diabetes were enrolled in the study (1). All pa-

${ }^{1}$ Neurology, Internal Medicine, Sakura Medical Center, Toho University, Japan, ${ }^{2}$ Clinical Physiology Unit, Sakura Medical Center, Toho University, Japan and ${ }^{3}$ Diabetes and Metabolism, Internal Medicine, Sakura Medical Center, Toho University, Japan Received: June 30, 2017; Accepted: November 21, 2017; Advance Publication by J-STAGE: February 9, 2018 Correspondence to Dr. Ryuji Sakakibara, sakakibara@sakura.med.toho-u.ac.jp 
Table. The Three Objective Tests Performed in Screening for Diabetic Neuropathy.

\begin{tabular}{|c|c|c|c|}
\hline & method & abnormality & relevant nerves \\
\hline $\begin{array}{l}\text { nerve } \\
\text { conduction } \\
\text { study }\end{array}$ & $\begin{array}{l}\text { motor \& sensory nerves } \\
\text { in the four extremities } \\
\text { (median, ulnar, tibial, } \\
\text { superficial peroneal, } \\
\text { sural) }\end{array}$ & $\begin{array}{l}\text { distal symmetric } \\
\text { sensorimotor } \\
\text { polyneuropathy [ } 22 \\
\text { nerve conduction } \\
\text { deviates abnormal } \\
\text { (peroneal motor nerve } \\
\text { conduction velocity \& } \\
\text { sural amplitude)] }\end{array}$ & $\begin{array}{l}\text { large diameter limb } \\
\text { fiber: myelinated } \\
\text { A }(\mathrm{A} \alpha-\mathrm{A} \beta), \mathrm{B} \text { fibers } \\
(\text { mean diameter } 8-15 \\
\mu \mathrm{m})\end{array}$ \\
\hline $\begin{array}{l}\text { post-void } \\
\text { residual urine } \\
\text { measurement }\end{array}$ & $\begin{array}{l}\text { transcutaneous bladder } \\
\text { echography just after } \\
\text { voiding }\end{array}$ & $>50 \mathrm{~mL}$ residual & $\begin{array}{l}\text { small diameter bladder } \\
\text { fiber: myelinated, } \\
\text { unmyelinated } \\
\text { Adelta-C fibers (mean } \\
\text { diameter } 1-3 \mu \mathrm{m} \text { ) }\end{array}$ \\
\hline $\begin{array}{l}\text { postural blood } \\
\text { pressure } \\
\text { measurement }\end{array}$ & $\begin{array}{l}\text { blood pressure } \\
\text { measurement on lying } \\
\text { and } 5 \text { min after active } \\
\text { standing }\end{array}$ & $\begin{array}{l}>-20 \mathrm{mmHg} \text { systolic } \\
\text { pressure fall }\end{array}$ & $\begin{array}{l}\text { small diameter } \\
\text { perivascular fiber: } \\
\text { myelinated, } \\
\text { unmyelinated } \\
\text { Adelta-C fibers (mean } \\
\text { diameter } 1-3 \mu \mathrm{m} \text { ) }\end{array}$ \\
\hline
\end{tabular}

tients were referred for screening for diabetic neuropathy, irrespective of their symptoms. The study population included 61 men and 49 women [mean age, 59.3 years (31-85 years); mean disease duration, 14.0 years (5-30 years); mean HbA1C, $10.1 \%$ (5.1-16.3\%)]. With the exception of 12 patients who were treated with oral sulphonylurea, thiazolidine derivatives or dipeptidyl peptidase-4 inhibitors, most were untreated patients with $\mathrm{HbAlc}$ values that ranged from 5.1 to $7.2 \%$. None had comorbid diseases that might cause postural hypotension or urinary dysfunction (i.e., multiple system atrophy or Parkinson's disease). None were taking drugs that might interfere with postural hypotension or urinary dysfunction. All patients were able to walk independently, and no patients had numbness in the extremities or dizziness on standing. All patients completed a urinary questionnaire (international prostate symptom score, IPSS, which is used in neurological diseases). We chose three objective tests to screen for diabetic neuropathy. 1) Somatic neuropathy: motor and sensory nerve conduction study [NCS, bilateral median, ulnar, tibial, superficial peroneal and sural nerves; Aalpha and B large fiber; typical distal symmetric sensorimotor polyneuropathy (DSPN) is a symmetrical length dependent sensorimotor polyneuropathy attributable to chronic hyperglycemia, metabolic derangement, and microvessel alteration. An abnormality of NCS that may be subclinical appears to be the first objective and quantitative indication of DSPN. We used Dyck's criteria 5 (abnormal $\Sigma 2$ nerve conduction deviation (peroneal motor nerve conduction velocity and sural amplitude)) (2). The normal limit of NCS in our institute was described previously (8)]. 2) Bladder neuropathy: ultrasound-based measurement of the post-void residual (PVR) volume (measured just after voluntary voiding, abnormality $>50 \mathrm{~mL}$ (9), A-delta/C small fiber). 3) Periarterial neuropathy: postural blood pressure measurement (Schellong test), between lying to active standing (9) (abnormality, >-20 $\mathrm{mmHg}$ (10): A-delta/C small fiber) (Table). We also exam- ined the relationship between the PVR volume and the HbAlc value and duration of diabetes. Fisher's exact probability test, Spearman's rank correlation coefficient, and Student's $t$-test were used to analyze the statistical significance of differences. All patients gave their informed consent before participating in the study.

\section{Results}

IPSS revealed moderate symptoms (IPSS $>8 / 35$ ) in 9 men and 4 women. The PVR volume was not related to the HbAlc value, while it was clearly related to the duration of diabetes $(\mathrm{p}<0.05)$ (Fig. 1). NCS abnormality, an abnormal PVR volume and postural hypotension were noted in 74 (67\%), 19 (17\%, almost the same volume in men and women) and $36(33 \%)$ of the subjects, respectively. In particular, most patients were unaware of post-voiding urinary retention. There were clear relationships between NCS and an abnormal PVR volume $(\mathrm{p}<0.05)$, postural hypotension and an abnormal PVR volume $(\mathrm{p}<0.05)$, and NCS and postural hypotension $(\mathrm{p}<0.01)$ (Fig. 2). There were also subjects who had NCS abnormality alone (40/110, 36\% in total; 40/ $74,54 \%$ of patients with NCS abnormality), an abnormal PVR alone (3/110, 3\% in total; 3/19, $16 \%$ with an abnormal PVR volume) and postural hypotension alone (5/110, 4.5\% in total; 5/36, $14 \%$ of the patients with postural hypotension).

\section{Discussion}

Previously, it was not well known whether bladder dysfunction occurs without somatic neuropathy, or whether bladder dysfunction is related to postural hypotension in patients with diabetes (11). To answer these questions, we chose three objective tests, which are not painful, easy to perform in elderly individuals, and applicable to all subjects. 

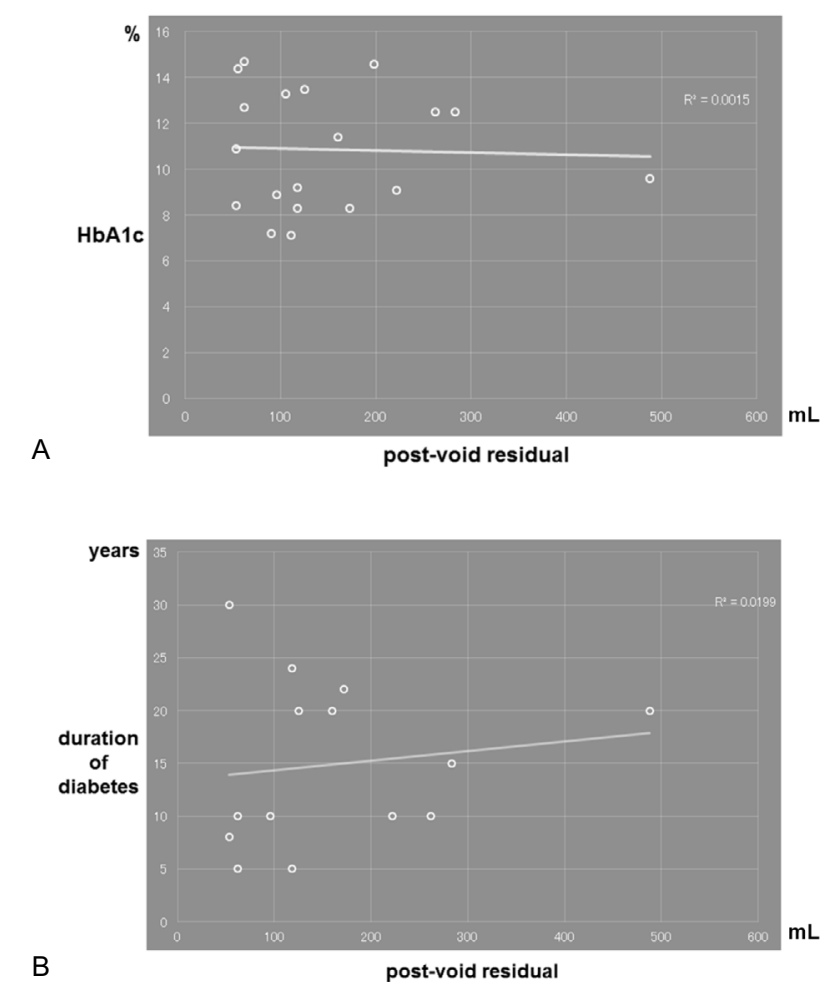

Figure 1. The relationship between the post-void residual volume and the HbA1c value (A), and the duration of diabetes (B). The post-void residual volume was not related to HbA1C value, while it was clearly related to the duration of diabetes $(\mathbf{p}<0.05)$.

The results of the present study showed that $17 \%$ of the diabetic subjects had an abnormal PVR volume. Notably, most patients were unaware of their urinary retention; this is in accordance with the findings of previous reports (12). The PVR volume was associated with the duration of diabetes ( $p$ $<0.05$ ), which is also in accordance with the findings of previous reports (4). However, the correlation coefficient was rather low (R2=0.0199); this might have also been affected by a case involving a patient with an extremely high PVR volume $(500 \mathrm{~mL})$.

To the best of our knowledge, we showed-for the first time-that bladder neuropathy was correlated with somatic and peri-arterial neuropathies $(\mathrm{p}<0.05)$. These findings indicate that bladder, somatic and peri-arterial neuropathies might share the same pathological process, which could include hyperglycemia-induced molecular changes (i.e., the intra-neuronal polyol cascade) or ischemia of the vasa nervosum $(13,14)$.

The results of the present study also showed that a proportion of subjects had an abnormal PVR volume alone (16\% of the subjects with an abnormal PVR volume), without somatic or peri-arterial neuropathy. We do not know the exact reason for this discrepancy. However, bladder-specific pathophysiology might include over-distension injury (due to polyuria) and changes in the urothelium $(15,16)$. In addition, there are different nerve receptors in the bladder and vessels (muscarinic M3 receptors and alpha-1A/D receptors

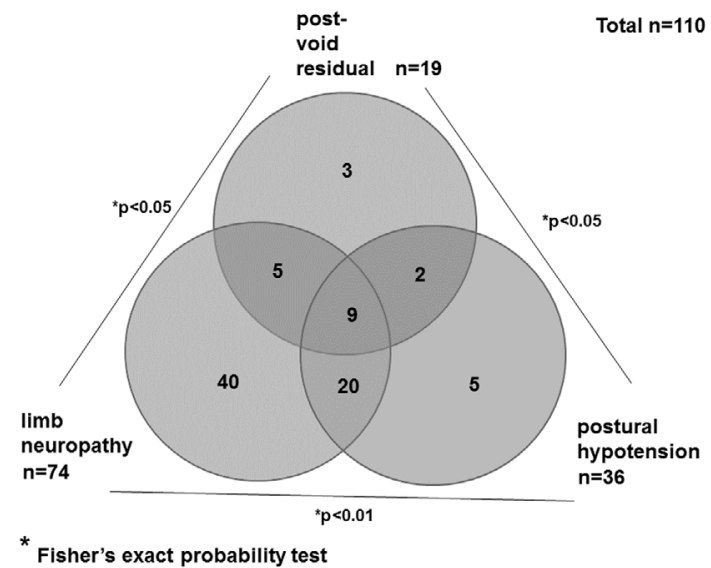

Figure 2. The abnormalities in the three objective tests and their relationships.

are abundant in the lower urinary tract, while alpha-1B receptors are abundant in the arterial wall) (17). This finding is clinically relevant and the regular measurement of the PVR volume seems necessary in diabetes as bladder neuropathy might occur insidiously in such patients.

The present study is associated with some limitations. We only measured the PVR volume and did not investigate the urodynamics or perform a prostate ultrasound examination to investigate bladder neuropathy. Thus, prostatic hyperplasia in men and storage dysfunction in both sexes might have been missed. Further studies that include a bladder diary and a urodynamics study are warranted.

In conclusion, bladder dysfunction was correlated with somatic and periarterial neuropathy. On the other hand, in $17 \%$ of the patients with bladder dysfunction, bladder dysfunction occurred without somatic or periarterial neuropathy; thus, the regular measurement of the PVR volume seems necessary.

The authors state that they have no Conflict of Interest (COI).

\section{References}

1. Seino Y, Nanjo K, Tajima N, et al.; Committee of the Japan Diabetes Society on the Diagnostic Criteria of Diabetes Mellitus. Report of the committee on the classification and diagnostic criteria of diabetes mellitus. J Diabetes Investig 1: 212-228, 2010.

2. Dyck PJ, Albers JW, Andersen H, et al; Toronto Expert Panel on Diabetic Neuropathy. Diabetic polyneuropathies: update on research definition, diagnostic criteria and estimation of severity. Diabetes Metab Res Rev 27: 620-628, 2011.

3. Yamaguchi C, Sakakibara R, Uchiyama T, et al. Overactive bladder in diabetes: a peripheral or central mechanism? Neurourol Urodyn 26: 807-813, 2007.

4. Yamaguchi C, Sakakibara R, Uchiyama T, et al. Bladder sensation in peripheral nerve lesions. Neurourol Urodyn 25: 763-769, 2006.

5. Mitsui T, Kakizaki H, Kobayashi S, Morita H, Matsuyama K, Koyanagi T. Vesicourethral function in diabetic patients: association of abnormal nerve conduction velocity with vesicourethral dysfunction. Neurourol Urodynam 18: 639-645, 1999.

6. Rapidi CA, Karadreas N, Katsifotis C, Benroubi M, Petropoulou 
K, Theodoreu C. A combined urodynamic and electrophysiological study of diabetic cystopathy. Neurourol Urodynam 24: 1-7, 2005.

7. Soylu A, Akinci A, Yilmaz U, Sarier M, Aslan M, Ozcan C. Sympathetic skin responses in type-1 diabetic children: relationship to urodynamic findings. Neurourol Urodynam 25: 243-248, 2006.

8. Sawai S, Sakakibara R, Uchiyama T, et al. Acute motor axonal neuropathy presenting with bowel, bladder, and erectile dysfunction. J Neurol 254: 250-252, 2007.

9. Homma Y, Ishizuka O, Ozono S, et al.; Committee Members, The Japanese Urological Association. Clinical Guideline for Benign Prostatic Hyperplasia. Richhill Medical, Tokyo, 2011.

10. Gilman S, Low P, Quinn N, et al. Consensus statement on the diagnosis of multiple system atrophy. American Autonomic Society and American Academy of Neurology. Clin Auton Res 8: 359-362, 1998.

11. Bansal R, Agarwal MM, Modi M, Mandal AK, Singh SK. Urodynamic profile of diabetic patients with lower urinary tract symptoms: association of diabetic cystopathy with autonomic and peripheral neuropathy. Urology 77: 699-705, 2011.

12. Yu HJ, Tai TY, Lee WC, Wu HP, Liu SP, Chen J. Unrecognized voiding difficulty in female type 2 diabetic patients in the diabetic clinic. Diabetes Care 27: 988-989, 2004.
13. Van Poppel H, Stessens R, van Damme B, Carton H, Baert L. Diabetic cystopathy: neuropathological examination of urinary bladder biopsies. Eur Urol 15: 128-131, 1988.

14. Nirmal J, Tyagi P, Chuang YC, et al. Functional and molecular characterization of hyposensitive underactive bladder tissue and urine in streptozotocin-induced diabetic rat. PLoS One 9: e102644, 2014.

15. Watanabe T, Miyagawa I. Characteristics of detrusor contractility during micturition in diabetics. Neurourol Urodynam 18: 163-171, 1999.

16. Hanna-Mitchell AT, Ruiz GW, Daneshgari F, Liu G, Apodaca G, Birder LA. Impact of diabetes mellitus on bladder uroepithelial cells. Am J Physiol Regul Integr Comp Physiol 304: R84-R93, 2013.

17. Sakakibara R, Hattori T, Uchiyama T, et al. Are alpha-blockers involved in lower urinary tract dysfunction in multiple system atrophy? A comparison of prazosin and moxisylyte J Auton Nerv Syst 79: 191-195, 2000.

The Internal Medicine is an Open Access article distributed under the Creative Commons Attribution-NonCommercial-NoDerivatives 4.0 International License. To view the details of this license, please visit (https://creativecommons.org/licenses/ by-nc-nd/4.0/).

(C) 2018 The Japanese Society of Internal Medicine Intern Med 57: 2165-2168, 2018 